Reviews in Medicine

\title{
Infectious diseases and AIDS
}

\author{
P.D. Welsby
}

Department of Infectious Diseases, City Hospital, 51 Greenbank Drive, Edinburgh EH10 5SB, UK

Infections and infectious diseases are such wide topics that a comprehensive account would be tedious. Therefore I have had to be selective and have included only those topics which a general reader should find interesting and important. Inevitably acquired immunodeficiency syndrome (AIDS) predominates.

\section{AIDS \\ Introduction}

The bad news. There are about 9 million people infected with human immunodeficiency virus (HIV) and one infection per 250 adults. A shocking little diagram ${ }^{1}$ shows the geographical distribution and the sex of those affected. In the United States there are one million infections with one infection per 75 men and one per 700 women. In Africa there are 6 million infections with one infection per $\mathbf{4 0}$ males and one per 40 females. One source ${ }^{2}$ estimated that by 2005 Uganda without AIDS would have had a population of 37 million, but now with AIDS the population will probably be only 22 million with one third of adults infected with HIV.

Sex is the major factor: the World Health Organisation estimates that at least 250 million sexual infections (including all known pathogens) are transmitted in the world each year. HIV is a 'standard' sexually transmitted disease and the final (already horrific) extent is uncertain. There is no doubt that future medical historians will class HIV as the most significant event in world history. Certainly HIV transcends all geographical and political borders. The spread of the HIV epidemic has been briefly and dramatically summarized. ${ }^{3}$

The derivation of HIV has always been contentious. A good review by a virologist working at the Institute of Cancer Research in London ${ }^{4}$ emphasizes that no one knows the derivation with certainty, and details all relevant theories including the more outlandish theories that the ill-informed

Correspondence: P.D. Welsby, F.R.C.P. (Ed.) always mention. The suggestion that HIV started life as a 'harmless contaminant' of an animalderived human vaccination is dismissed, in my view correctly, although viruses have crosses into new species with lethal results and, in the initial process of developing live oral polio vaccines, African Green Monkeys were used for propagation.

The DNA sequences of HIVs can be compared to other similar viruses and assessments can be made of the chance of mutatory leaps or evolutionary developments. The discovery of simian immunodeficiency virus $\left(\right.$ SIV $\left._{\text {mac }}\right)$ was followed by the discovery of HIV-2 but, although superficially similar, they were sufficiently different to be considered as separate viruses. SIV $_{\text {mac }}$ might have been a forerunner of HIV-2; however, SIV $_{\text {mac }}$ has not been found in wild macaques. Monkey viruses could have infected humans via monkey bites, scratches, eating monkey meat, or ritual preparations obtained from wild monkeys.

Several different SIVs have been investigated and some cause no disease in their natural host but can do so in other hosts. There is a striking similarity between HIV-2 and a SIV from the Sooty Mangabey monkey (SIV $\mathbf{s m m}_{\text {smm }}$ ) and the geographical distribution of the two viruses is similar. SIV $_{\mathbf{s m m}}$ are similar to SIV $_{\text {mac }}$ and there is a possibility that SIV $_{\text {smm }}$ could be the ancestor of HIV-2 or SIV SIac $_{\text {mac }}$ but perhaps there might be an as yet unidentified ancestor for all three - mathematical estimations are that no more than 40 years would be required for the evolution of differences betwen HIV-1, HIV-2 and SIV mac. $_{\text {A retrovirus, }}$ SIV $_{\text {cp2 }}$ has been isolated from wild chimpanzees which is similar to HIV-1, the cause of human AIDS. The simian-human connection is also the subject of several papers in Nature which have been well reviewed. ${ }^{5}$

Because the HIV epidemic in the United States is several years ahead of that in the United Kingdom, we can use their experience to predict our future. From January 1988 to June 1989, active surveillance of HIV seropositivity by anonymous testing of 89,547 samples (excluding patients with diagnoses often associated with HIV infection) at sentinel urban hospitals revealed a seroprevalence of $1.3 \%$, ranging from 0.1 to $7.8 \%$. HIV infection 
was highly concentrated in males (presumably mostly homosexual or bisexual) in areas with a low prevalence but, in areas where the seropositivity rate was higher, the male to female ratio decreased proportionally (implying spread by intravenous drug abuse or heterosexually). At two hospitals in communities with the highest prevalence of AIDS, $1.1-3.8 \%$ of those infected were $15-19$ years old and $18-22 \%$ of all men aged 25 to 40 years old were seropositive. The authors suggest that in certain high prevalence areas routine screening is indicated. ${ }^{6}$

Because some seronegative patients will be infected and infectious perhaps all laboratory specimens from patients in certain areas should be treated as seropositive without the need to screen. However, it is now in asymptomatic patients with less than $500 \mathrm{CD} 4+$ cells $/ \mathrm{mm}^{37}$ and mildly symptomatic ${ }^{8}$ patients' interest to know that they are infected because treatment is now available that will delay disease progression. I believe that, in certain high seroprevalence areas, every patient should be routinely told the local seropositivity rate, and asked if they want to be tested and know their result. Those who do not want to know their result (even if tested) and those specimens from those who decline to be tested should routinely be treated as if positive.

On the 17 May 1991 the preliminary results of unlinked anonymous testing in England and Wales were made available. The overall prevalence of HIV infection in women attending certain antenatal clinics in inner London was one in 500 (ranging from one in 200 to one in 1000). In other parts of the country the positivity rate was one in 16,000 . Amongst those attending certain sexually transmitted disease clinics in inner London one in 100 heterosexual men was infected and one in 500 heterosexual women. The positivity rate in homosexual and bisexual men was one in five.

\section{Drugs for HIV infection}

New drugs for treating HIV infection have to show appreciable advantages over zidovudine and importantly such drugs should not exhibit adverse interactions with other drugs which may be used in AIDS patients. For example, it is known that combinations of zidovudine and gangciclovir are poorly tolerated with up to $82 \%$ of such patients developing severe to life-threatening haematological toxicity. ${ }^{9}$

Three studies ${ }^{10}$ have both contributed to our knowledge and emphasized areas of ignorance concerning the indications for treatment with zidovudine. For those of us humble enough to admit we are perpetually trying to remedy our state of ignorance the American-style 'state of the art' statements are useful but always contain further worrying areas of ignorance for us all to share. Study 016 demonstrated that zidovudine delayed progression of HIV disease and produced little toxicity in patients with mildly symptomatic HIV infection and fewer than $0.5 \times 10^{9}$ CD4 cells/l. Study 019 demonstrated that a total daily dosage of $500 \mathrm{mg}$ zidovudine reduced progression to advanced disease in asymptomatic patients with fewer than $0.5 \times 10^{9} \mathrm{CD} 4$ cells/l, and severe toxicity was rare. Study 002 demonstrated that doses smaller than $250 \mathrm{mg}$ four hourly were as effective, resulted in a better survival rate, and were considerably less toxic. Worryingly, resistance of HIV to zidovudine develops in patients given a high dosage for 6 months but cross-resistance to other similar drugs has not yet been demonstrated. This multi-authored statement has as its main conclusion 'Therapy with zidovudine is recommended for both symptomatic and asymptomatic HIVinfected individuals whose CD4 counts are fewer than $0.500 \times 10^{9} / 1$.'

A British Medical Journal Editorial ${ }^{11}$ summarizes these same trials but ends on a distinct note of caution 'Any move to intervene in asymptomatic infection and to prescribe low doses [of zidovudine] should be approached with caution.' Development of resistance, continual outpatient attendances, and lack of information about the long-term effects of giving a drug with action against host cell genetic material all contribute to this praiseworthy sceptic-? ism.

\section{Some chest problems in AIDS}

Pneumothorax is an uncommon occurrence in AIDS. A review of 25 AIDS patients with pneumothorax ${ }^{12}$ reported that 10 were spontaneous, four occurred post-bronchoscopy, and 13 during mechanical ventilation. All patients had respiratory infections, usually with Pneumocystis carinii. Twelve of those who developed a pneumothorax during mechanical ventilation died within 10 days despite appropriate interventions. The authors stress that bilateral bulla formation accompanies Pneumocystis carinii pneumonia and the optimal surgical treatment would be bilateral pleurodesis, via a median sternotomy, because there is a risk of contralateral pneumothorax.

The role of steroids in the routine treatment of Pneumocystis carinii pneumonia has been debated for some time. Five studies are now available and have been well summarized ${ }^{13}$ and steroids are recommended. Once the exact mechanisms of pulmonary damage are elucidated more specific treatments will be possible, some of which should avoid the additional immunosuppression caused by corticosteroids. 
Mycobacterium tuberculosis infection and active disease is a well-recognized complication of immunodeficiency associated with AIDS. There are clear guidelines for the treatment of tuberculosis ${ }^{14}$ in the United Kingdom. Because Africa and North America are several years ahead of us in their experiences of the worldwide HIV epidemic and AIDS, we should look to them to see what problems may be in store for us. Tuberculosis is one such problem. A study from Zambia ${ }^{15}$ suggested that epidemics of reactivating tuberculosis were arising in those infected with HIV. Because the classical manifestations of tuberculosis depend substantially on the host's immune reactions it was not unexpected that the HIV-positive tuberculosis patients tended not to have classical upper lobe disease or cavitation: those with positive sputum cultures were less likely to have positive microscopy on sputum smears, implying delay in diagnosis, and of course tuberculosis is infectious especially for those with immunodeficiency. Combine these tendencies with drug resistance and problems will arise. One USA-based study from a single centre reported an abrupt onset of primary isoniazid and rifampicin resistance in a large number of patients (most of whom had HIVassociated immunosuppression) consistent with recent transmission. ${ }^{16}$ Further guidelines will be required. Should HIV-positive patients with pneumonia be isolated in rooms until the nature of the pneumonia is ascertained? Should all patients with known or suspected previous Mycobacterium tuberculosis infection receive prophylaxis? If so at what stage of their immunodeficiency? Should treatment be continued until death in AIDS patients who do develop tuberculosis? Almost certainly yes. But in what doses of which drugs after the classical treatment period is over? And finally how do we maximize prevention - which is currently not perfect? ${ }^{17}$

Nosocomial transmission of Mycobacterium tuberculosis infection from AIDS patients is another worry. Often therapies (inhalation therapy for Pneumocystis carinii pneumonia, for example) or investigation (inducing sputum for diagnostic purposes or bronchoscopy) of patients encourages exposure to respiratory derived droplets. An editorial ${ }^{18}$ advises, inter alia, the avoidance of unnecessary bronchoscopies, screening for tuberculosis, wearing of masks (ordinary masks are useless for protection of the wearer, however), environmental controls (ventilation of ward areas is progressively less effective in preventing infection while it is progressively more expensive to achieve, and even optimally functioning ventilation should have ultraviolet air disinfection), and source control. All these are counsels of perfection that few units will be able to achieve in cash-limited health care facilities even in the developed world.

\section{Social aspects of HIV infection}

The risks of occupational transmission of HIV are a subject of intense personal interest to all healthcare workers. The risk of transmission associated with a percutaneous exposure to blood from an HIV-positive person is about $0.3 \%$ per exposure ${ }^{19}$ and the risk of occupational mucous membrane or cutaneous exposures are likely to be substantially smaller. The risks of acquiring HIV from an HIV-positive blood transfusion are (hopefully were) $90 \%{ }^{20}$

The occurrence of profound immunodeficiency in the later stages of HIV predisposes both to opportunistic infections and unusual neoplasms (the immune system probably evolved to prevent infections and neoplasia) and thus there will always be a suspicion that infection is the cause for any unusual illness that occurs in the HIV positive. The problem is that microbiologists usually only screen for a limited number of pathogens. In the context of profound immunosuppression, negative or sterile results do not mean there is no infection present, but may mean that 'standard' investigations are inadequate. Bacillary angiomatosis is a proliferation of small blood vessels in the skin and viscera of immunocompromised hosts. The bacterium responsible (which may also cause cat scratch disease) has been seen but not grown. It has now been identified using the polymerase chain reaction $^{21}$ and is a ricketsia-like organism closely related to $R$. quintana. In the same issue of that journal, a newly recognized Gram-negative bacteria was described as causing fever and bacteraemia in patients, including HIV patients. ${ }^{22}$ The organisms in these two papers are very similar and might be identical.

The implication is that profoundly immunosuppressed patients provide a perfect culture media for all manner of pathogenic (and also classically non-pathogen) organisms. The longer we keep our immunosuppressed patients alive, the more sophisticated will our diagnostic facilities have to be. These will be costly and will contribute substantially to the overall costs of managing HIV infection, which are themselves substantial - the costs of universal precautions alone is thought to have cost the United States at least \$336 million in 1989.

A dramatic insight into the social, medical and political features of AIDS in central Africa is provided by a paper of depressing content. ${ }^{23}$ Once seropositivity rates rise above $10 \%$ the concept of high-risk groups has little practical relevance and HIV testing is hardly necessary. Tuberculosis is rampant in the seropositive with notification rates doubling in three years. Opportunistic infections reflect the background prevalence of indigenous pathogens: infections with cryptosporidium, salmonella, amoebae, and giardia are common. 
Pneumocystis carinii pneumonia is unusual. The reasons for this are uncertain: pneumocystitis infects $70 \%$ of Gambian children by the age of eight as judged by antibody prevalence studies ${ }^{24}$ but the impact is probably diminished by the prevalence of fatal tuberculosis.

The social consequences are simultaneously predictable and shocking. Tuberculosis apart, cryptococcosis poses significant problems in parts of Africa. In one hospital in Rwanda ${ }^{25}$ more money is spent in treating cryptococcal meningitis than in treating tuberculosis, and cryptococcal meningitis is the third most common AIDS-defining illness in HIV-positive patients.

It has been known for many years that infectious illnesses have often had more effect on the outcome of wars than brilliant generalship ${ }^{26,27}$ (a notable exception being the Battle of Waterloo in which a brisk attack of piles and the treatment thereof interfered with Napoleon's generalship). It has been shown that the pattern of spread of HIV and the later inevitable development of AIDS in Uganda was partially at least related to the patterns of ethnic recruitment into the Ugandan National Liberation Army after the overthrow of Idi Amin in $1979 .{ }^{28}$

The epidemiology of spread of AIDS will no doubt be a subject of interest for many years and the role of air transport, trade routes, sexual behaviour, and drug-taking patterns will be shown to have conspired to cause millions of deaths.

The overall prognosis for patients with HIV (whether or not they have had an AIDS-defining illness) is useful knowledge when assessing the effects of treatment. It is also of relevance to individual patients but of course group statistics cannot be applied to individuals. Patients can be given guidance using such statistics with appropriate explanations. In one study ${ }^{29}$ the mean survival of HIV-infected patients receiving anti-retroviral treatment was 12.1 months once the CD4 count fell below 50 cells $/ \mathrm{mm}^{3}$ and nearly all deaths occurred in patients with fewer than $50 \mathrm{CD} 4$ cells $/ \mathrm{mm}^{3}$.

Dramatic breakthroughs are good news, but not for the medical fraternity when it cannot assess the veracity of such claims because the details of trials, if any, are not rapidly available. I learnt from reading The Sunday Times that a trial of acyclovir plus zidovudine had to be stopped because the survival at 1 year with the combination was double that of AZT alone. As this revelation occurred between Christmas and the New Year no information was available from the manufacturer (Wellcome) of both these products before I had to deal with AIDS patients who expected me to decide whether or not I should give them this combination. Clarification was available in the Observer the next Sunday. The claims were 'totally discredited!' As far as one of the trial coordinators knew, the trial was stopped because the drug was effective against cytomegalovirus and the survival rates had improved. A Wellcome spokeswoman said as far as she knew the trial was halted simply because acyclovir did not work against cytomegalovirus. In the New Scientist another coordinator said that none of the doctors responsible for the trial had yet seen all the data. Surely there must be a better way for preliminary results to be communicated (or at least be made available) to the medical fraternity. Even a prerecorded summary on a telephone hotline would have been helpful to me and my patients. As it was, I had to rely on conference communications and previous pilot studies. ${ }^{30}$ It is possible to have results released early. A large multicentre trial in the United States ${ }^{31}$ was halted after it was shown that cytomegalovirus retinitis patients on foscarnet lived longer (12 months compared with 8 months) than those on ganciclovir. Both agents were equally efficacious in stopping progression of cytomegalovirus retinitis and in preventing deterioration of vision in patients recently diagnosed as having cytomegalovirus retinitis.

The editors of journals concerned with AIDS will surely have to respond to the need for 'fast track' reporting of results. Although it may preempt the considered final, and inevitably multiauthored paper, the statistician who halted the trial really ought to publish his or her reasons, even if a full discussion of the significance of the results is? left open to await final publication.

Zidovudine had to be released with haste on humanitarian grounds well before the usual investigations were performed. The most appropriate dosage to be used at various stages of HIV infection is still debated. A randomized double blind trial ${ }^{32}$ suggested that zidovudine should be limited to $400-600 \mathrm{mg}$ daily in patients with AIDS or advanced HIV infection.

In Edinburgh the prevalence of HIV infection in injection drug users is high. Of all known HIVpositive patients admitted to one hospital, 208 patients accounted for 612 admissions, 180 of which were for chest-related disorders. ${ }^{33}$ In the UK more than $50 \%$ of such admissions would be associated with Pneumocystitis carinii infection but in Edinburgh only $27 \%$ were. Most (54\%) of the Edinburgh patients had bacterial chest infections and it is likely that most were related to HIV immunodeficiency (short of CDC stage 4 disease) and multifactorial associations of injection drug use. Medical care provision planning in areas of high prevalence of injection drug use should take into account such HIV-, but not AIDS- or ARCrelated workload. 
Vaccination against HIV is seen by many to be 'the answer' to the worldwide epidemic of HIV which is now, in certain areas, endemic but I do not think that this optimism is justified. It is certainly unlikely that, in the near future, any drug will be able to destroy or remove all traces of HIV once it has been incorporated into the host cell nucleic acid. What should be achieved is prevention or long-term, preferably lifelong, containment or blocking of HIV by means of drugs or vaccination. Unfortunately, the high mutation rate of HIV and the possibility of HIV transmission by virusinfected cells or by free virus, make vaccine development difficult.

There are two possible aims for a successful HIV vaccine. Firstly the prevention of infection pre- or post-exposure. Secondly the stimulation of host immune mechanisms such that HIV is permanently suppressed.

There are numerous practical problems associated with prevention of infection by a vaccine. The major problem is that no vaccine confers $100 \%$ protection, especially when challenge is with large infecting doses which may arrive via various at-risk routes. Obviously a vaccine would have to be free of serious side effects and confer a high protection rate. Long-term trials will be necessary before it can be concluded that any vaccine has prevented minute, and therefore undetectable, infection which might only assume significance many years later.

To be effective in population terms, a preventative HIV vaccine would have to be given before the at-risk exposure: in other words the vaccine would have to be a routine vaccination for all members of a population given prior to the age at which sexual activity or intravenous drug abuse are likely - and even then such a 'population successful' vaccine will not reduce the need for individuals to use safe sex and safe needle-sharing measures.

A vaccine which would permanently suppress HIV in those infected would seem to be possible provided that it were given before HIV had not impaired the host's ability to respond adequately. It would also be important that tests were available which would distinguish between vaccination responses and HIV-induced responses.

The fact that HIV can change its antigenic makeup is yet another reason why vaccination or immunological cure may be problematic. For example, from one patient no fewer than four viruses of different biological properties have been isolated sequentially. ${ }^{34}$ If biological properties also include resistance to anti-retroviral drugs the problems would of course be compounded, the more so if the patients involved transmitted his or her current virus to another person.

\section{Prophylaxis against infection}

Because of the persisting predisposition towards infection in end-stage HIV infection, once a therapeutic course of treatment has been given for a specific opportunistic infection, as a general principle, prophylactic treatment should be continued until death in patients: who (1) are on zidovudine; (2) have had Pneumocystis carinii pneumonia; (3) have had significant herpes simplex infections; (4) have had AIDS dementia complex responsive to zidovudine; (5) have had progressive CMV retinitis; (6) have had oesophageal or invasive candidiasis; (7) have infections transmissable to others (especially other immunocompromised patients); and (8) probably most patients who have had central nervous system toxoplasmosis unless there has been no evidence of treatment efficacy (including slowing of disease progression), unacceptable toxicity or side effects, severe dementia, or the patient is plainly near to death. The implications of this is that patients now, and increasingly in the future, will accumulate a long list of prophylactic treatments. Lack of drug toxicity and interactions are a priority for the pharmaceutical industry to address.

\section{Chickenpox}

Chickenpox is usually an occupational hazard of attending school. Treatment is possible with acyclovir but the question is whether acyclovir, which is free of significant side effects but which is certainly not cheap, should be given. A controlled trial of acyclovir $(20 \mathrm{mg} / \mathrm{kg}$ four times daily) in normal children ${ }^{35}$ showed that children had fewer varicella lesions, had fewer lesions after day 3 of therapy, had accelerated progression to crusting and healing, less itching, and fewer residual lesions after 28 days. Fever and constitutional symptoms were less. In short acyclovir is effective and will allow children to return to school earlier-provided they could be treated early in the course of the illness, perhaps even after a contact if they were known to be non-immune. Official guidance will be needed soon to prevent haphazard usage of acyclovir.

A live attenuated varicella vaccine is available which can prevent chickenpox (or will it merely postpone infection for decades if immunity wanes?) and has been shown to reduce the incidence of zoster in children with leukaemia. ${ }^{36}$

Should varicella vaccine become a routine vaccination of childhood? This would minimize the incidence of infection in childhood but would cause an increase in the age at which infection would occur in the non-immune and, because chickenpox, in common with many childhood infections, is 
more severe in adults, this might have serious implications. Vaccination of children would not eradicate infection for decades because a proportion of those, about $30 \%$, who had had natural chickenpox would develop shingles and thus reintroduce infection into the community. Nearly all of us can be considered to be varicella carriers. Booster revaccination in the elderly might be required to prevent chickenpox and also could be used to boost natural chickenpox-induced immunity in the elderly so they do not develop shingles.

\section{Childhood leukaemia}

Sporadic occurrences of rare diseases are compatible with various aetiologies including rare manifestions of common infections or common manifestations of rare infections. An epidemiological study ${ }^{37}$ revealed that children aged $0-4$ years who lived in rural new towns (where the population density is higher and derived from more diverse origins) had a higher incidence of leukaemia than did children from urban 'overspill' new towns. These findings supported the hypothesis that leukaemia represented a rare response to a common infection which would have been encouraged by the coming together of large numbers of people. In each case there was a significant deficit in other age groups consistent with immunizing effects of the postulated infection. Similar considerations affect the incidence of feline leukaemia in which different social settings affect the intensity of likely leukaemogenic viral exposure. The virus(es) presumed to be responsible for human disease are as yet unidentified, but may well be retroviruses.

Another population-based study of leukaemia in children under the age of 15 revealed that, in 1950-1953, but not thereafter, there was a significant excess of leukaemia in county groupings with the highest proportion of servicemen and was mostly caused by an excess in children less than two years old in rural areas. ${ }^{38}$ Such areas showed significantly more notifications of one infection, poliomyelitis. Although associations need not necessarily be casual, the findings reported suggested transmission of an infection amongst adults and thus to the fetus.

\section{Chlamydia pneumoniae strain TWAR}

The expression 'atypical pneumonia' was used to describe pneumonias which were different from 'typical' pneumococcal pneumonia with lobar consolidation or 'standard' bronchopneumonia. More recently the number of organisms which can cause atypical pneumonia has been extended by the addition of a new chlamydial organism.

The order Chlamydiales has one family, Chlamydiaceae, and one genus, Chlamydia. There are two recognized species Chlamydia psittaci (which causes psittacosis, also known as ornithosis) and Chlamydia trachomatis (which causes trachoma and sexually transmitted genital tract infections). Recent studies have revealed another organism, Chlamydia pneumoniae strain TWAR(TWAR refers to the laboratory codes of the first two isolates) that shares the Chlamydia genus specific antigen but differs from both 'earlier' organisms. This new organism appears to be a primary human pathogen without an animal or bird reservoir, the incubation period and infectivity being uncertain. Epidemiological and serological studies have shown that about $10 \%$ of patients with pneumonia and about $4 \%$ of those with bronchitis have TWAR infection, and furthermore epidemics can occur. As with other chlamydia organisms, tetracycline and erythromycin are the most effective drugs but, unlike the other chlamydia organisms, sulphonamides are not effective. In one review ${ }^{39}$ doses of $2 \mathrm{~g}$ daily of tetracycline or erythromycin for 10-14 days is made: even so, relapses may occur. Plainly this organism will have to be considered in the differential diagnosis of atypical pneumonia.

\section{Chronic fatigue syndrome}

Evidence continues to accumulate that this syndrome is associated with organic changes which cannot be produced by psychiatric illness. An investigation of the immune status of 100 patients revealed significant reductions in the number of circulating T-cells including helper/inducer T-cells and suppressor/cytotoxic T-cells. A reduction in function of in vitro and in vivo immunological functions was also demonstrated. Reduced immunoglobulin levels were also found. ${ }^{40}$ There is also no doubt that immune activation occurs in patients with major symptoms. ${ }^{41}$ Compared to controls there were reduced CD8 suppressor cell numbers, and evidence of activation markers compared to controls and patients with other diseases. The authors could not correlate their findings with serological evidence of infection with any known human viruses (the author of this review would suspect an as yet unknown retrovirus). Thus there is no doubt that there is immune system dysfunction in this syndrome but the question is whether this is a primary event or merely an epiphenomenon and, more importantly, whether therapy aimed at repairing such defects is beneficial and, if it is, can we then focus on what particular elements of the therapy are producing the effect so that we may then be able to pinpoint accurately the cause and be 
able to give more specific treatment and perhaps prophylaxis.

Enthusiasts have advocated many therapies for chronic fatigue syndrome, including medical, paramedical and 'fringe' remedies. Two interesting papers, both describing the response of chronic fatigue syndrome to intravenous immunoglobu$\operatorname{lin}^{42,43}$ reached conflicting conclusions (this is reassuring: enthusiasts usually always find positive results, especially if studies are not 'physician blinded'). Although the two groups of patients treated were not strictly comparable, one team of researchers ${ }^{42}$ gave five times the standard dose of immunoglobulin and achieved a statistically significant benefit: the other group gave a standard dose and did not observe any significant benefit (although such a dose should have reversed minor deficiencies in immunoglobulin subclasses). Interestingly the patients who improved symptomatically also improved on testing of immunological parameters. The expense of such treatment is, however, very significant and side effects were common - such that the trials could not be properly blinded. The contrasting results are well reviewed in an accompanying editorial. ${ }^{44}$

Candida hypersensitivity as a cause for chronic fatigue and other unhappinesses (including premenstrual tension, gastrointestinal symptoms and depression), has had its advocates and therapeutic enthusiasts. A randomized double blind trial utilizing nystatin revealed that both nystatin and placebo reduced symptoms but nystatin did not significantly reduce systemic symptoms. ${ }^{45}$ No doubt the next stage trials of systemically absorbed anti-candida therapy are at present under way: but in the meantime is it ethical (or legally sensible) to treat with a placebo?

The discovery of a specific marker for this syndrome will be the next breakthrough, and this will allow in-depth investigation of the pathogenesis. At present the differential diagnosis list is so wide that it is difficult to focus the necessary high-technology expensive investigations on unequivocally genuine cases.

One unfortunate side effect of chronic fatigue syndrome has been the huge number of 'occasional tests' performed on patients, the results of which provide no therapeutically relevant information. Sporadic testing for Coxsackie B titres was one such test and the total cost must have been enormous. Serological tests available for detecting Coxsackie B virus antibodies do not help diagnose (and certainly do not help to treat) the postviral fatigue syndromethe results merely reflect the background level of infection in the population. ${ }^{46}$ So stop testing unless it is part of a scientifically evaluable study!

Most syndromes have, in the past, and will, in the future, turn out to have more than one cause. With the postviral fatigue syndrome there is controversy about the criteria for diagnosis and even doubt in the minds of some about the existence of the syndrome as an organic entity, so it is not surprising that different studies report on different aspects of noncomparable series of patients and come to different conclusions. Nevertheless, evidence is accumulating that a significant proportion of patients clinically diagnosed do have primary organic dysfunctions that could explain their symptoms. Sixty consecutive patients ${ }^{47}$ with postviral fatigue syndrome underwent intensive investigation to exclude other disorders and there were 41 control patients. Fifteen (25\%) and 10 controls (24.4\%) had important serological findings. However, significantly more patients than controls had enteroviral RNA sequences in muscle (32/60 compared with 6/41) suggesting that persistent enteroviral infection of muscle may occur in some patients and may have an aetiological role in the syndrome.

Other viruses may also have a role in pathogenesis of chronic fatigue. Herpes virus type 6 was grown in three out of seven patients with chronic fatigue syndrome. ${ }^{48}$ The problem with such reports is that the future administration of appropriate antiviral agents will be required before it will become obvious whether such viruses are pathogenically relevant or merely epiphenomena.

\section{Cryptosporidiosis}

Safe disposal of human sewage is assumed in Britain. Nevertheless faecal-oral spread infections are possible, especially if the organisms concerned may be resistant to standard water-purifiying procedures. One British outbreak of cryptosporidiosis was attributed to contaminated river water that had been used to supplement borehole water, ${ }^{49}$ another outbreak appeared to be caused by the failure of normal treatment to remove cryptosporidial oocysts. ${ }^{50}$ and another outbreak was caused by what are charitably called 'significant plumbing defects' which allowed undetected ingress of sewage into swimming pool water.$^{51}$ Cryptosporidiosis may be a nasty disease and, apart from hopeful reports of therapy with newer macrolide antibiotics, there is no known curative treatment.

\section{Enterohaemorrhagic Escherichia coli infections}

E. coli serotype 0157:H7 was first recognized as an enteric pathogen in $1982^{52}$ which initiated a haemorrhagic colitis which, unlike Shigella dysentry, caused copious diarrhoea usually without faecal leukocytes. Since the initial description it has become apparent that certain other serotypes can cause this syndrome. ${ }^{53}$ 
Apart from gastroenteritis, it has been increasingly appreciated that infection with this organism can precipitate the haemolytic uraemic syndrome, ${ }^{54}$ almost certainly by the production of a verotoxin which damages endothelial cells. Importantly, antibiotics do not shorten the duration of diarrhoea ${ }^{54}$ and indeed the use of antibiotics at the time of exposure may increase the risk of infection with this serotype..$^{55}$

\section{Gastroenteritis}

Simple useful non-expensive clinical research is often neglected in favour of expensive high technology laboratory research. A refreshingly simple paper ${ }^{56}$ analysed 239 patients with diarrhoea admitted consecutively to an infectious diseases unit. Patients with inflammatory bowel disease often had long-standing diarrhoea, blood in the faeces, anaemia, leucocytosis, thrombocytosis, a raised ESR and a reduced serum albumin. However, the most striking differential feature was the platelet count: a count of greater than $450 \times 10^{9} / 1$ was found in $59 \%$ of patients with inflammatory bowel disease but only in $1.6 \%$ of those with infective diarrhoea. Thus a raised platelet count in a patient admitted with 'acute gastroenteritis' suggests a diagnosis of inflammatory bowel disease.

It is a widely unknown fact that a large proportion of chicken carcasses purchased in Britain are contaminated with salmonella (our protection is based on adequate cooking of the carcass and the salmonella). Many sporadic salmonella infections caused by inadequate home cooking are doubtless never recongized as such and it is only when numerous cases occur (invariably in relation to large-scale catering) that the problem of carcass contamination is highlighted. Hospital outbreaks receive disproportionate prominence because patients mostly develop their gastroenteritis whilst in hospital and the problem becomes evident. Other large-scale catering outbreaks escape notice: hotel guests have often distributed themselves around the country by the time they develop symptoms and they do not usually keep in touch with one another, so that hotel-related outbreaks are hard to recognize (the exception is weddings when people do tend to keep in touch after their gathering). An illustration of such problems ${ }^{57}$ is that, in one year, $54 \%$ of chicken carcasses delivered to a psycho-geriatric hospital carried one or more types of salmonella, and every consignment contained infected carcasses. Thirty-eight per cent of sewer swabs revealed similar organisms presumably the sewage organisms had passed through the patients. The kitchens changed policy and ordered only cooked carcasses and there was a significant reduction in the isolation rates, to around $2 \%$, of salmonella from the sewers.

From January 1992 European Community (EC) regulations state that broiler chickens found to contain salmonella will not be sold as fresh meat but will have to be cooked or irradiated.

A useful editorial ${ }^{58}$ was prefaced by a simple statement about anti-diarrhoeal drugs worthy of repeated emphasis - 'None work, and many may be dangerous' - but also mentioned was the reason why so many doctors use anti-diarrhoeal agents. The treatment indicated (glucose-based oral rehydration therapy) does not decrease the number of stools and therefore parents do not consider that the diarrhoea is getting better. Newer food-based oral rehydration therapies, which do reduce the number of stools, ${ }^{59}$ are an important advance and should reduce what need there is for antidiarrhoeal agents. Additionally, malnourished children with diarrhoea may be disadvantaged by even temporary replacement of food by fluids.

\section{Global warming: some consequences}

In an article entitled 'Global warming - which could equally have been titled 'Global warning' some predictions are made concerning the likely disease risks. ${ }^{60}$ Changes in vegetation patterns will change farming practices and zoonoses will be affected. Wildlife might prosper and transmit infection (badgers with tuberculosis could pass the infection to cattle and thence onwards to humans). Insect vectors of infection will be affected. The most common British tick, Ixodes ricinus, will change its distribution and the zoonotic infections it may transmit (babesiosis, louping ill, and Lyme disease) may become more frequent on commons. Despite these risk the author of this paper thinks problems will be relatively minor and that 'most people will be more appreciative of the general climatic improvement'.

\section{Haemophilus influenzae type b infections: prevention}

There are six antigenically distinct encapsulated serotypes of $H$. influenzae. Type b is the most virulent and can cause serious infections, particularly in children in whom meningitis, epiglottitis and pneuomonia are prominent: most significant disease occurs in the under-fives with an estimated annual incidence of 33.4 per $100,000 .{ }^{61}$

A comprehensive survey of invasive Haemophilus influenzae infections has been published. ${ }^{62}$ In Gwynedd in Wales the annual incidence of Haemophilus influenzae type b infections was 3.2 cases $/ 100,000$, most being in the under-fives with an incidence of $84.6 / 100,000 .{ }^{63}$ Predominant conditions were pneumonia in adults and meningitis in 
children. A total of $1.9 \%$ of isolates were resistant to both chloramphenicol and ampicillin. Even though this percentage is low, illnesses were severe and so alternative antibiotics should be used as first-line treatment for infections that might be caused by Haemophilus influenzae. By the age of five most children have acquired antibody suggesting that they have been exposed to Haemophilus influenzae type b or other cross-reacting organism products. The polysaccharide capsule is a major virulence factor and immunization is a distinct possibility, and indeed a large trial was performed in the 1970s which showed protection in children over the age of 18 months, but not under this age. ${ }^{64}$ Linkage of the polysaccharide antigen to a protein carrier improves efficacy and such vaccines are used in infants in Finland, the USA and Canada.

An English study has revealed that nearly all children vaccinated developed antibody levels associated with immunity ${ }^{65}$ and if confirmed no doubt Haemophilus influenzae vaccination will be added to the routine vaccinations of childhood: vaccination has been free of significant side effects. The history, theory and practice of Haemophilus influenzae immunization have been well reviewed. ${ }^{66}$

In the meantime, the conventional guidance for chemoprophylaxis in contacts of Haemophilus influenzae type $\mathrm{b}$ disease was given in a recent report from the Public Health Laboratory Service Communicable Diseases Surveillance Centre. (A reference is not given because, until recently, the publication was not officially listed for quotation: this unhappy situation has been rectified and their valuable reports are now 'in the public domain'.) Rifampicin, the drug of choice, is recommended in a dose of $20 \mathrm{mg} / \mathrm{kg} /$ day up to a maximum of $600 \mathrm{mg}$ daily for 4 days. (This differs from recommendations for meningococcal prophylaxis which is $10 \mathrm{mg} / \mathrm{kg}$ twice daily for 2 days to a maximum of $600 \mathrm{mg}$ twice daily.) Groups recommended for prophylaxis are the following. (1) All household members (except pregnant women, any person with severe impairment of hepatic function, and children under the age of 3 months) irrespective of age, where there is an index case of Haemophilus influenzae type $\mathrm{b}$ meningitis and another child less than 3 years old. (2) All room contacts where two or more cases of Haemophilus influenzae type b disease have occurred in a playgroup, nursery or crèche within 120 days, that is where spread of the organism may have occurred within the group (exceptions as above). (3) Index cases of Haemophilus influenzae type $\mathrm{b}$ disease prior to discharge from hospital; except children under 3 months. The dose of rifampicin recommended eliminates Haemophilus influenzae from the nasopharynx is about $95 \%$ of cases. A detailed review of chemophrophylaxis is available. ${ }^{67}$

An Australian study ${ }^{68}$ revealed that $69 \%$ of patients with invasive disease had positive throat swabs on admission falling to $9 \%$ after 3 days treatment. At 6 weeks follow-up 32\% of patients who had not received rifampicin had positive swabs but only $8 \%$ of those who had received rifamipicin were positive. Amongst the household contacts $33 \%$ of children and $7 \%$ of adults were colonized and the colonization rates were similar whatever the nature of the index case disease. The case for prophylaxis is clear.

\section{Handwashing: will doctors ever learn?}

That handwashing reduces the incidence of nosocomial infection has been confirmed many times. The effect of two educational programmes separated by 5 years in a 16-bedded intensive care unit was assessed: ${ }^{69}$ before the first programme the nosocomial infection rate was $33 \%$ with a handwashing rate of $28 \%$ after patient contact. After the programme, the nosocomial infection rate was $12 \%$ with a handwashing rate of $81 \%$. Predictably old habits returned ( $23 \%$ handwashing) with a nosocomial infection rate of $33 \%$. After the second programme $60 \%$ handwashing resulted in an infection rate of $10 \%$. Continually reinforced routine handwashing (especially by doctors) after each patient contact in intensive care units should be instituted.

\section{Helicobacter pylori infection}

Recurrent abdominal pain in children is a common paediatric problem and in some children no organic cause is apparent. These children often receive a variety of descriptive non-aetiological diagnoses. Fortunately treatable organic causes are being discovered in some. The role and management of Helicobacter pylori infections in children has been well reviewed in the Postgraduate Medical Journal ${ }^{70}$ but it is still uncertain if all children with recurrent abdominal pain should have gastric infection with this organism excluded and, if so, how far should investigations proceed: few would deny that there is 'a need for upper gastrointestinal endoscopic examination in children with dyspeptic symptoms', but is this reasonable in other children with recurrent abdominal pain that is not obviously dyspeptic?

An increased risk of gastric carcinoma in the Japanese, who have a high incidence, is strongly associated with $H$. pylori infection. ${ }^{71}$ However, most persons infected will not develop gastric carcinoma and other factors obviously operate. The infection might be an epiphenomenon, or might cause an increased propensity because the infection causes other problems which might be the 
more direct cause of carcinoma, or the infection and the cancer might have a shared cause and the infection and the cancer have no direct causal association. Obviously more research is needed into gastric carcinoma (undoubtedly of multifactorial aetiology) and the role of $H$. pylori. Whether therapeutic eradication of Helicobacter would reduce the incidence is not known.

\section{Hepatitis}

Giant cells are often found in childhood hepatitis and are often thought to be a non-specific response to tissue damage, although paramyxoviruses can cause syncytial giant-cell formation: in particular measles can cause a hepatitis with giant cell formation. Ten patients have been described whose hepatitis may have been caused by a paramyxovirus. ${ }^{72}$ Logically this would, if confirmed, have to be labelled hepatitis $\mathrm{G}^{73}$

The Canadian economist, J.K. Galbraith, invented the term 'the conventional wisdom' and went on to remark that it was surprising how often this conventional wisdom remained unchallenged and, when challenged, was discovered to have little basis in fact. The conventional wisdom is that abstinence from alcohol should be advised after an attack of acute hepatitis, although the durations of abstinence advised differ from authority to authority. Those of us who deal with drug abusers who often continue to abuse multiple substances of abuse (including alcohol) after, and even during, acute hepatitis, are somewhat sceptical about the giving of such advice to such patients (who usually recover completely). If drug abusers recover, how will the general hepatitic population fare if they drink whilst recovering from acute hepatitis? A paper detailed 87 patients with hepatitis (A in 36, B in 34, non-A, non-B in 17), who were randomized either to a moderate alcohol intake (a mean of $26 \mathrm{~g}$ daily) or to continued complete abstinence. ${ }^{74}$ There were no significant differences between the two groups at any time, suggesting that a moderate alcohol intake during convalescence from acute viral hepatitis does not seem harmful.

\section{Hepatitis B}

Certain outbreaks of hepatitis B (HB) infections are associated with a high mortality rate and, until recently, the explanation given included high infecting doses or proven or postulated other infectious cofactors (the former including other hepatitic viruses such as delta agent). Detailed analysis of hepatitis B viruses associated with high mortality outbreaks revealed mutant strains. ${ }^{75,76}$ In the patients reported, the HB surface antigen (HBsAg) and anti-HBe, but not $\mathrm{HBeAg}$, were present. This is unusual because the levels of $\mathrm{HBeAg}$ usually correlate with the reproduction of hepatitis B virus and hence, via a variety of mechanisms, the severity of the resulting hepatitis. Thus naturally occurring viral mutations in the hepatitis B virus genome may predispose those infected to more severe liver damage. A useful editorial explores the implications. $^{77}$

Twelve outbreaks of hepatitis B associated with infected surgical health care workers (in all but one outbreak the worker being $\mathrm{HBeAg}$-positive) were reported between 1975 and 1990 in England, Wales and Northern Ireland. ${ }^{78}$ An outbreak was defined as two or more cases of (clinical or subclinical) cases of acute hepatitis B after an invasive surgical procedure performed by a team which included an infected health care worker. Although the number of secondary cases depended on the extent of contact tracing to detect sub-clinical infections, 91 surgical patients were identified who had acquired acute hepatitis B (56 were icteric and 35 were asymptomatic): four of these had transmitted the infection to their sexual partners. In two instances the surgical speciality was general surgery, in three gynaecology, in five cardiothoracic surgery, one was unknown and in one the infected person has assisted in general, gynaecological and cardiothoracic surgery. Only three surgeons had received all or part of a course of hepatitis B vaccine. Any surgeon reading this who has not been vaccinated should, without delay, initiate his or her vaccination because permanent hepatitis B carriage, especially with evidence of spread of infection to patients, will be a career-limiting infection.

The cause of idiopathic chronic liver disease, by definition, must be obscure. A fascinating study ${ }^{79}$ using virion capture by high-affinity monoclonal antibody and DNA amplification by polymerase chain reaction identified 36 patients with low levels of hepatitis B DNA in whom all other conventional tests for hepatitis B were negative. Eleven patients with 'classical' antibody evidence of previous hepatitis B were also positive, suggesting the presence of active disease in patients who would normally be considered to be immune. Thus 'conventionally $\mathrm{HBs} A \mathrm{~g}$-negative' hepatitis B infection may be responsible for some cases of idiopathic liver disease - the authors suggest that up to $90 \%$ of idiopathic liver disease may be attributed to hepatitis $B$ infection.

\section{Hepatitis C}

The risks of hepatitic $\mathrm{C}$ acquisition by the sexual route are thought to be low but there is still a risk. A study conducted from a sexually transmitted disease clinic $^{80}$ provided strong evidence for both heterosex- 
ual and homosexual sexual transmission. A study of patients from a highly epidemic focus of chronic liver disease in Japan ( $24 \%$ of 218 patients older than 30 years and a further $21 \%$ without symptoms had laboratory tests indicating chronic liver disease) revealed a hepatitis $\mathrm{C}$ seropositivity rate of $7.5 \%$. The carriage rate of HBsAG was less than $1 \%$. Wives with seropositive husbands were more likely to be positive than those with seronegative husbands. ${ }^{81}$

What role does hepatitis $\mathrm{C}$ play in fulminant hepatic failure? An American study of 15 patients with fulminant hepatic failure revealed no patients with detectable antibodies or hepatitis C RNA ${ }^{82}$ but in Japan (where hepatitis $\mathrm{C}$ is more common) nine out of 21 patients with fulminant hepatic failure had 'some evidence' of hepatitis $C$ infection. ${ }^{83}$ Further studies are needed but plainly the role of hepatitis $\mathrm{C}$ will vary on a geographical basis.

\section{HTLV-I infection}

Human T-cell lymphotropic virus Type I (HTLVI) is unrelated to HIV and does not cause AIDS. HTLV-I is an RNA tumour-invoking virus which, in particular, causes adult $T$-cell leukaemia and lymphoma and a slowly progressive spastic paraparesis known as tropical spastic paraparesis. ${ }^{84}$ The chances of leukaemia developing in those infected is ${ }^{10}{ }^{85}$ and the chance of tropical spastic paraparesis is probably also low. The interval between exposure and illness (if any) is shorter for the neurological manifestations than for the leukaemia or lymphoma which takes about 30 years. ${ }^{86}$

HTLV-I transmission occurs by blood transfusion, intravenous drug abuse, sexual intercourse, and from mother to child, both in utero and via breast feeding. Is HTLV-I yet another virus that should be routinely screened for in blood donors? The prevalence in United States blood donors is $0.025 \% .{ }^{87}$ British prevalence rates are probably lower, reflecting the lower proportion of people derived from West and central Africa where the virus is endemic. The cost of screening blood donations for unusual pathogens that unusually might cause serious illness will be high and the number of potential pathogens (both known and soon to be discovered) is increasing. Probably the lawyers will force the initiative in Britain, but in Southern Japan there are over 1,000,000 infected persons ${ }^{88}$ and screening thus more indicated.

\section{Legionnaires' disease}

Certain potential pathogens lurk in the environment waiting, as it were, for the environment to change or be changed, before they seize their opportunity to cause human disease. Legionella pneumophila is such a pathogen which has no doubt been lying around in wet environments for millenia. It had to await the development of 20th century necessities such as showers and cooling towers, utilizing cascading water to cool the air in ventilation systems before it could be presented in a condition that could infect human lungs. Given that it is an uncommon disease, it took the occurrence of an outbreak before epidemiologists and others could discover the causative organism. Subsequently many cooling tower outbreaks have been identified, but all clinicians are familiar with sporadic cases. But are they too associated with cooling towers? A Glasgow based study ${ }^{89}$ analysed the location of patient's homes and cooling towers, and found that there was an inverse association between distance of residence from any cooling tower and risk of non-outbreak infection. The authors predictably advise that better maintenance of cooling towers should prevent non-outbreak cases of Legionnaires' disease. In the meantime I advise living upwind!

\section{Lyme disease}

Before one can confirm any diagnosis, one has to suspect it. Lyme disease in Britain may be suspected in areas where the infection is known to be endemic in the tick population. A review of dermatological manifestations ${ }^{90}$ is useful although there is debate about whether European clinical manifestations differ from those in the United States. The most specific manifestations are erythema migrans, secondary (multiple) erythema migrans, Borrelia lymphocytoma, and acrodermatitis chronica atrophicans.

Classical erythema migrans is usually found in body areas where ticks feed - underwear lines and intertriginous areas, for example - but only infrequently on palms, soles and mucous membranes. Three to $\mathbf{3 0}$ days after the tick bite a lesion with a centrifugal border develops which may enlarge to an average of $15 \mathrm{~cm}$ in diameter (but up to $68 \mathrm{~cm}$ have been recorded). In more than $50 \%$ of cases, there is an associated flu-like illness with fever, myalgias, arthralgias, malaise, fatigue or headache. Secondary (or multiple) erythema migrans occurs several days to several weeks after the initial lesion. Individual lesions tend to be similar to the initial lesion but tend to be smaller, to migrate less, and lack indurated centres.

Borrelia lymphocytoma has several other names. Lesions occur at the same time as the tick bite or even up to 10 months later. There is a firm red, red-brown, or red-purple nodule or plaque usually found on the ear in children, or on the nipple or 
areola in adults. It is often tender and there may be regional lymph node enlargement.

Acrodermatitis chronica atrophicans is a unique late complication of Lyme disease. It is a biphasic phenomenon with an initial erythematous or violaceous discoloration in doughy or swollen skin which form nodules or plaques. Lesions often occur on the extremities but may occur on the face or trunk. The lesion expands and may wax and wane, and this may continue for weeks to years before atrophy sets in: in this stage the skin has a glistening appearance with a prominence of blood vessels. Other dermal manifestations of Lyme disease including scleroderma-like lesions may also be found. All are well documented and described in this well-illustrated review. In the same issue of the Annals of Internal Medicine the current recommendations for diagnosis and treatment are outlined.91

Lyme disease was first identified in 1975 when there was an unusual epidemic of childhood arthritis. Most diagnosed patients were treated but some, who spontaneously improved, were not treated. What happened to these patients? After early manifestations including facial palsy, meningitis and atrioventricular nodal block, the frequency of attacks of arthritis decreased and all $\mathbf{4 6}$ children studied had no arthritis within 9 years although two had keratitis, and two neuroborreliosis. ${ }^{92}$

\section{Malaria}

What exactly are the risks of acquiring malaria in various parts of the world? A prospective study ${ }^{93}$ has yielded useful information. A total of 2,948 British residents returning to Britain and 1,052 British residents with confirmed malaria were studied. Rates of infection per 100,000 travellers to the following areas were: Oceana 4,100, West Africa 375, East Africa 172, Latin America 12, Far East 2, and Middle East 1. Immigrants who returned to visit Ghana and Nigeria were at greatest risk (1,303 and 952 per 100,000, respectively). The non-use of prophylaxis ranged from 17 to $58 \%$. The efficacy of chloroquine plus paludrine against falciparum malaria was $73 \%$ in West Africa and $54 \%$ in East Africa, whereas the efficacy of Maloprim (pyrimethamine plus dapsone) was $61 \%$ in West Africa but only $9 \%$ in East Africa. Noncompliant visitors to West Africa were at 2.5-fold higher risk of infection than were compliant visitors. These are disappointing results from both visitors and drugs: it should not be forgotten, however, that prophylaxis might not prevent malaria but almost certainly will result in a less aggressive attack.

Drug-resistant malaria is an increasing problem and the mechanisms have been well reviewed in a leading article. ${ }^{94}$ Suggested mechanisms include drug pressure, extensive use of subcurative doses of anti-malarials, migration, and increased virulence of the resistant parasites. If drug pressure were responsible, universally high levels of resistance would be expected in malarious countries, but this does not always occur; in certain areas there is high continued high chloroquine sensitivity where there has been intensive haphazard use of chloroquine. Additionally the distribution of chloroquineresistant malaria is non-uniform despite uniform drug usage. Two important inferences can be drawn. Firstly chloroquine may continue to provide adequate clinical efficacy even in areas with reported resistance and awaiting responses to therapeutic trials of chloroquine without microscopic confirmation of the diagnosis are risky.

Interestingly malaria does not function as an opportunistic infection in HIV-positive individuals, even in those with AIDS itself. ${ }^{95}$ of 1,527 'clinically suspicious' in-patients in Kampala, $61 \%$ were HIV positive of whom $52 \%$ fulfilled the clinical case definition for AIDS. No association could be found between HIV infection and malaria in adults or children. Plasmodium falciparum infection was found in $18 \%$ of these patients with no difference in rates of infection, or in parasitaemia counts between those HIV positive and HIV negative. Additionally, the response to treatment was the same.

Anyone who may have to deal with severe or complicated malaria must have immediate access to an important publication ${ }^{96}$ which comprehensively reviews all relevant aspects in depth. Any clinician will find clinically relevant and academically interesting information in abundance. A table comparing severe malaria in adults and children (page 10) was particularly useful and a list of common errors of anti-malarial chemotherapy (page 47) was daunting: delay in starting treatment; unjustified withholding of a drug because of exaggerated or unfounded fears of toxicity (quinine in pregnancy, for example); incorrect dosaging; improper use of loading doses (a loading dose of quinine should not be given if the patient has received quinine or mefloquine within the preceding 12-24 hours); dangerous route of drug administration (all patients with severe malaria should initially receive treatment intravenously); failure to elicit a history of recent chemotherapy; unjustified cessation of treatment (the dangers of uncontrolled falciparum infection do not contraindicate on-going therapy of patients who are hypoglycaemic, have haemolysis with haemoglobinuria, or are pregnant entering premature labour, or who have fetal distress); failure to control the rate of intravenous infusions; failure to prevent cumulative effects of antimalarial drugs; failure to switch patients to oral 
treatment as soon as they can swallow; unnecessary continuation of treatment after an adequate course; failure to recognize that therapeutic priorities in severe malaria are different from those in uncomplicated malaria; delay in considering obstetrical intervention in women with severe malaria in late pregnancy; unnecessary endotracheal intubation; misdiagnosis of respiratory distress (pulmonary oedema, aspiration pneumonia, and acidosis may be confused clinically); failure to control convulsions; failure to recognize and treat severe anaemia; use of inappropriate and potentially dangerous ancillary therapies (including corticosteroids, anti-inflammatory agents, osmotic agents, dextran, heparin, adrenaline, prostacyclin and cyclosporin A); and finally, delay in starting peritoneal dialysis.

\section{Monoclonal antibodies}

The pathogenesis of septic shock is very complex ${ }^{97}$ and treatment of the initiating bacterial infection is a major consideration, but only a partial solution to the morbidity and mortality associated with septic shock. Indeed, over-vigorous anti-bacterial attack may cause liberation of mediators of cellular damage, thereby making the patient worse before making him or her better; in certain circumstances this worsening may mean irreversibility or even death. Numerous forms of treatment are on the therapeutic horizon to complement antibiotics. The use of convalescent serum from those who had recovered from certain infections was often the only treatment available for seriously ill patients in the pre-antibiotic era. Once antibiotics arrived the benefit of such 'blunderbuss' antibody therapy became relatively slight and such therapy became relatively less important. But what of a welltargeted specific antibody? In May 1991, a monoclonal antibody (HA-1A) developed for the treatment of Gram-negative bacteraemia ${ }^{98}$ was made commercially available in The Netherlands. This antibody binds specifically to the lipid A domain of endotoxin and had previously been shown to prevent death in laboratory animals with Gram-negative bacteraemia. In humans with Gramnegative bacteraemia followed to death or day 28 , there were 45 deaths among 92 who received placebo and 32 among the 105 who received HA-1A $(P=0.014)$. For those with Gram-negative bacteraemia and shock there were 27 deaths among 47 who received placebo and 18 among 54 who received HA-1A $(P=0.017)$. There were no major side effects. Patients who did not have Gramnegative sepsis showed no benefit.

This initial report of treatment of Gram-negative endotoxaemia describes an undoubted innovation which, if its original promise (and the promise of further products to follow) is fulfilled, will cause every budget holder to have a chronic anxiety attack - indeed HA-1A was described as a 'Budgetbuster' in the British Medical Journal: the cost per single treatment is about $£ 2,200$. Such a price is easy to justify given the costs of research and development (which were rumoured to be in the region of 50 million dollars).

The incidence of Gram-negative bacteraemia is difficult to estimate but the mortality is high despite all previous therapies (including antibiotics), so the use of such high-cost treatment is justified. However, the diagnosis of Gram-negative bacteraemia can only be confirmed once blood cultures are known to be positive and many patients might have to be treated empirically (and expensively) whilst confirmation or denial of Gram-negative bacteraemia is awaited: additionally it seems likely that high-risk patients might have to be treated prophylactically with resulting total costs being even higher. But perhaps other predictably expensive monoclonal antibody techniques will enable the rapid identification of Gram-negative endotoxin so that HA-1A administration could be targeted accurately. The cost of new technology will become a major consideration in the years to come.

\section{Plagues}

Epidemics of infectious diseases or the establishment of widespread endemic diseases have occurred in the past and will continue in the future. An important review paper ${ }^{99}$ justifies the author's contention that any new infection that will pose a threat to humanity will probably come from animals and will need to have acquired the capacity for both efficient and direct spread from human to human. Most human infections that are derived from animals do not spread onward from the infected person to others and thus die out in the human population (Influenza $\mathbf{A}$ infections are an exception). Human to human spread via the respiratory tract would seem to be ideal for rapid spread to large numbers of people - sexual transmission would be slower as would faecal-oral spread.

Heightened surveillance will be necessary to identify, at a very early stage, if there is any tendency for animal pathogens to successfully enter the human population. In this regard it is reassuring to note that heightened surveillance identified HIV at an early stage (31 patients out of the population of the USA) yet their significance was soon realized. Had HIV developed person-toperson spread via the respiratory route then humanity would have been annihilated! 


\section{Pneumococcal vaccine}

Pneumococcal infection may be serious with pneumonia ('the Captain of the Men of Death'), septicaemia and meningitis being the main causes of morbidity and mortality. The situation is more serious than a superficial appraisal might suggest because there is an increasing problem with pneumococcal strains resistant to multiple antibiotics, and prevention may in future be an effective approach.

A pneumococcal vaccine is available but how much protection is given to immunocompetent recipients? A study reporting comparative vaccination rates of patients with proven pneumococcal infection and a matched control group showed that the vaccine had an efficacy of $61 \%$ in immunocompetent patients. ${ }^{100}$ As expected the vaccine was not efficacious against pneumococcal infections of a serotype not contained in the vaccine.

The implications of this and other vaccine work are enormous. The number of routine vaccinations that could/should be given will multiply (Haemophilus, hepatitis, and meningococcal vaccines are in the queue, as HIV will be in future).

\section{Polymerase chain reaction}

This ingenious technique was invented in 1985 and allows the repeated copying (amplification) of small stretches of DNA present in trace amounts. Heating of the DNA extracted from the cell under test causes the double helix to separate into two strands. Short sequences of DNA of known sequences, 'primers', are added and will attach to one end of each strand of the target DNA if it is present. A bacterial enzyme, DNA polymerase, makes new DNA starting from the primer molecules and, in the presence of a supply of nucleic acid bases, makes complementary sequences of the test DNA. Thus two double-stranded helices are made and, if the cycle of heating and reforming is repeated many times, an exponential increase in the amount of test DNA is produced.

Since the precise sequence of DNA present can be copied, complete genetic characterization is possible and the DNA can be identified as belonging to a particular strain or serotype of a particular species within a particular family of organisms.

This technique is exquisitely sensitive and, under optimal conditions, can detect the presence of miniscule amounts of DNA, even if the organisms cannot be seen or cultured. It is invaluable when alternative laboratory tests do not exist, as for certain viruses which cannot be cultured. Genetic identification is becoming increasingly useful in epidemiological studies.

Whilst simple in principle, controls are essential and the polymerase enzyme can be inhibited by even trace amounts of macromolecules (as may be present in certain bacterial cell walls).

\section{Rabies}

Three patients developed rabies in the USA. ${ }^{101}$ Virological studies revealed that they had been infected with viral strains that were characteristic of strains present in their country of origin (Laos, Phillippines and Mexico) but these patients, as far as could be ascertained, had not visited these countries for 6 years, 4 years, and 11 months. There was no evidence of other rabies in their human or animal contacts. Thus rabies might have a longer incubation period than previously thought.

\section{Retroviruses}

My previous review (Postgraduate Medical Journal, 1990, 66: 807-817) suggested that, 9 years hence, the retrovirus section would dominate. Progress is being made.

A retrovirus has been identified in patients with Sjogren's syndrome: ${ }^{102}$ identification of a microorganism of course does not prove causation but nevertheless the circumstantial evidence is suggestive - dryness of mouth and eyes is sometimes seen in HIV (also a retrovirus) infection.

The aetiology of motor neurone disease is still debated: ${ }^{103}$ similarities to polio may indicate a viral aetiology. There is no evidence yet of retrovirus infection but the evidence points strongly to an environmental cause such as a virus or a chemical agent. ${ }^{104}$

\section{Schizophrenia}

Despite the claim by some psychoanalysts that mental illness is all in the mind there is accumulating evidence that physical illness, by affecting the brain, can cause mental illness. The developing brain in utero is vulnerable to several infections and so it is not surprising that later mental illness might result. An interesting paper ${ }^{105}$ found that, 5 months after the peak prevalence of the 1957 Influenza A epidemic, the number of births of individuals who later developed schizophrenia was $88 \%$ higher than the mean number of births in the corresponding periods of the preceding and following 2 years. The interesting question is whether these patients have an associated microstructural disorder (which would probably be irreversible) or an on-going metabolic dysfunction (which might well be treatable). 


\section{Gender and infections}

Diseases caused by infection may have differing attack rates in different sexes and differing severity in different sexes. However, it was not widely known (to me at least) that, with some infectious diseases including measles ${ }^{106}$ and apparently chickenpox, the severity is influenced by the sex of the person from whom the infection was acquired. The most simple explanation could be that people of opposite sex are 'closer' than people of same sex and infecting doses of pathogens are consequently higher, but there is no evidence for this. Alternatively, some viruses possibly may take sex determinants from host cells which could facilitate infection of opposite sex host cells, or viruses derived from someone of the same sex might be more easily controlled. Some fascinating research needs to be done!

\section{Smoking versus bacteria}

The effect of cigarette smoke, both from mentholated and non-mentholated cigarettes, on common bacterial pathogens has been studied in vitro ${ }^{107} \mathrm{Gram}$-positive cocci, including Streptococcus pneumoniae and Staphylococcus aureus were inhibited to a greater extent than Gram-negative rods, including Klebsiella, Enterobacter and Pseudomonas. Thus smokers have a propensity to be colonized with Gram-negative organisms - and this was confirmed with culture studies in vivo.

\section{Travel}

Facts and figures are intrinsically fascinating: hence the popularity of the Guiness Book of Records. A leading article ${ }^{108}$ provides these in abundance. Since 1949 world-wide international travel has increased 13-fold with a 25-fold increase of those travelling beyond Europe. In 1988 an estimated 1.99 million British residents spent, on average, 31 nights in tropical and sub-tropical countries. Thirty-five per cent travelled to Africa. $35 \%$ to Asia, $12.5 \%$ to the Caribbean, $4.5 \%$ to South America and the rest enjoyed cruises and tours. Interestingly the incidence of imported malaria remained static at about $1.3 / 1,000$ travellers. World-wide one third of travel brochures contained no information about health, only a half contained general health advice and only $11 \%$ contained specific advice. Surveys of travellers departing for malarious areas reveals that travel agents only give advice about the risk of malaria to $15-28 \%$ of their customers. Only $14 \%$ of general practitioners who responded to a postal questionnaire correctly recognized four regions where chloroquine-resistant malaria was present. Only two-thirds of travellers who sought advice about malaria actually used chemoprophylaxis and $22 \%$ of international travellers were taking unnecessary prophylaxis. Travellers' diarrhoea occurs in $30-50 \%$ of people, of whom $30 \%$ may be thereby confined to bed. The risk of typhoid fever is $1 / 30,000$ and non-paralytic polio is $0.7-33 / 100,000$ travellers. Cholera is unusual in travellers from Britain and the vaccine efficacy is only about $50 \%$. Staying at home is safer!

\section{Tuberculosis}

Tuberculosis in developing countries is a major cause of morbidity and mortality. Probably onefifth of the world population is infected, harbouring tubercle bacilli in calcified primary complexes which, given a suitable opportunity, may reactivate to cause disease in the reactivee and those who inhale his sputum. Between 6-8 millon people develop tuberculosis with 2-3 million deaths each year: ominous figures that HIV will undoubtedly exacerbate. A useful review paper ${ }^{109}$ details the four methods for prevention; improvement of socioeconomic conditions, case-finding and treatment, chemoprophylaxis, and vaccination. Improvement of socio-economic conditions is a long-term solution but case-finding and treatment is the only feasible short-term method. Interestingly the authors summarize 35 papers on the efficacy of BCG vaccination and find results varying between 0 and $96 \%$. Worryingly the results from 10 trials suggests waning of BCG-conferred protection with the passage of time.

An ominously titled paper 'Is Africa lost?'110 details the problems with tuberculosis in Africa and with HIV-associated tuberculosis. Across subSaharan Africa there are 2.4 million people with tuberculosis and HIV. The practicalities are that 2 month courses of therapy for tuberculosis may be the maximum attainable, and perhaps cure rates of no more than $80 \%$ for tuberculosis will have to be accepted. BCG vaccination of all children must be a priority to stop them getting primary complex disease and thus a risk of subsequent reactivation.

What should be done with contacts of tuberculosis? Prophylaxis with isoniazid would be too expensive and there would be compliance problems. The authors mention the prospect of preventative immunotherapy (which would have to use a vaccine-like injection) which would lead to the elimination of long-term stasis of infecting bacilli and which would also leave the individual protected from reinfection. It would have to be safe, cheap, stable, easy to administer and (because of HIV) must not consist of live organisms. The author concludes that a tremendous amount of 
money and research is going into tuberculosis today, and asks how much of it is relevant to the problems of the real world. This comment could, of course, apply to most diseases.

In the meantime, apparently Dr Louis Sullivan, US Secretary of Health and Human Services, announced his endorsement of the goal of eliminating tuberculosis from the United States by the year 2010. I would not disagree with the goal but would not gamble any money on its achievement: I would put my money on the combination of intercontinental travel and HIV to ensure that tuberculosis is a continuing problem!

\section{Yersinea enterocolitica infections}

Yersinea enterocolitica infection often gives rise to non-gastroenteritic manifestations. A 10 year study ${ }^{111}$ of 458 hospitalized patients with Yersinea infection, proven by culture or serology, revealed a high incidence (64/4) of chronic diseases on admission (obviously these might represent coincidental

\section{References}

1. Communicable Diseases Report 1991, 1: 1. (Reproduced from WHO Global Programme on AIDS. Current and Future Dimensions of the HIV/AIDS Pandemic: A Capsule Summary, 1991.)

2. AIDS Analysis Africa 1991, March/April, African Analysts Ltd, London.

3. Mann, J. AIDS takes hold of the World. In The World in 1992. Economist Publications, London, 1991, pp. 96-97.

4. McClure, M. Where did the AIDS virus come from? New Scientist 1990, 126: 54-57.

5. Doolittle, R.F. Immunodeficiency viruses. The simian-human connection. Nature 1989, 339: 338-339.

6. St Louis, M.E., Rauch, K.J., Petersen, L.R. et al. Seroprevalence rates of human immunodeficiency virus infection at sentinel hospitals in the United States. $N$ Engl $J$ Med 1990, 323: 213-218.

7. Volberding, P.A., Lagakos, S.W., Koch, M.A. et al. Zidovudine in asymptomatic human immunodeficiency virus infection. $N$ Engl $J$ Med 1990, 322: 941-949.

8. Fischl, M.A., Richman, D.D., Hansen, N. et al. The safety and efficacy of Zodovudine (AZT) in the treatment of subjects with mildly symptomatic human immunodeficiency virus type 1 (HIV) infection. Ann Intern Med 1990, 112: 727-737.

9. Hochster, H., Dieterich, D., Bozzette, S. et al. Toxicity of combined ganciclovir and zidovudine for cytomegalovirus disease associated with AIDS. Ann Intern Med 1990, 113: $111-117$

10. National Institute of Allergy and Infectious Diseases. Stateof-the-art conference on azidothymidine therapy for early HIV infection. Am J Med 1990, 89: 335-344.

11. Swart, A.M., Weller, I. \& Darbyshire, J.H. Early HIV infection: to treat or not to treat. Br Med J 1990, 301: 825-826.

12. Byrnes, T.A., Brevig, J.K. \& Yeoh, C.B. Pneumothorax in patients with acquired immunodeficiency syndrome. $J$ Thorac Cardiovasc Surg 1989, 98: 546-550.

13. The National Institutes of Health-University of California Expert Panel for Corticosteroids as Adjunctive Therapy for Pneumocystis Pneumonia. Consensus statement. $N$ Engl $J$ Med 1990, 323: 1500-1505. disease, predisposing diseases, or diseases caused by unrecognized longstanding infection). More striking were the acute clinical manifestations: 189 had uncomplicated arthritis, 60 erythema nodosum, 54 liver dysfunction, 16 renal manifestations, nine Reiter's syndrome, eight iridocyclitis and eight neurological manifestations. Of 53 patients tested, 35 had histocompatibility antigen HLA-B27. Fiftysix had undergone surgery for right iliac fossa pain: mesenteric adenitis was found in 23 , terminal ileitis in 20, and other manifestations in 13. Plainly an infection to be avoided.

\section{The future}

In the short term, infectious diseases and infection will continue to compete with other diseases. In the long term, once cancer and heart diseases and the like are conquered, we can all look forward to dying of degenerative diseases of infection. So eat (well-cooked food), drink (uncontaminated water), and be merry (with one mutually faithful partner)!

14. Ormerod, L.P. (for subcommittee of Joint Tuberculosis Committee). Chemotherapy and management of tuberculosis in the United Kingdom: recommendations of the Joint Tuberculosis Committee of the British Thoracic Society. Thorax 1990, 45: 403-408.

15. Elliot, A.M., Luo, N., Tembo, G. et al. Impact of HIV on tuberculosis in Zambia: a cross sectional study. Br Med J 1990, 301: 412-415.

16. Pitchenik, A.E., Burr, J., Lafeur, M. et al. Outbreaks of drug-resistant tuberculosis at AIDS centre. Lancet 1990, 336: 440-441.

17. Glassroth, J., Bailey, W.C., Hopewell, P.C., Schecter, G. \& Harden, J.W. Why tuberculosis is not prevented. Am Rev Respir Dis 1990, 141: 1236-1240.

18. Nardell, E.A. Dodging droplet nuclei. Reducing the probability of nosocomial tuberculosis transmission in the AIDS era. Am Rev Respir Dis 1990, 142: 501-503.

19. Henderson, D.K., Fahey, B.J., Willy, M. et al. Risk for occupational transmission of human immunodeficiency virus type 1 (HIV-1) associated with clinical exposure. Ann Intern Med 1990, 113: 740-746.

20. Donegan, E., Stuart, M. \& Niland, J.C. Infection with human immunodeficiency virus type 1 (HIV-1) among recipients of antibody-positive blood donations. Ann Intern Med 1990, 113: 733-739.

21. Relamn, D.A., Loutit, J.S., Schmidt, T.M., Falkow, S. \& Tompkins, L.S. The agent of bacillary angiomatosis. $N$ Engl J Med 1990, 323: 1573-1580.

22. Slater, L.N., Welch, D.F., Hensel, M.S. \& Coody, D.W. A newly recognised Gram-negative pathogen as a cause of fever and bacteraemia. $N$ Engl J Med 1990, 323: 1587-1593.

23. Goodgame, R.W. AIDS in Uganda - clinical and social features. $N$ Engl J Med 1990, 323: 383-389.

24. Wakefield, A.E., Stewart, T.J., Moxon, E.R., Marsh, K. \& Hopkin, J.M. Infection with Pneumocystis carinii is prevalent in healthy Gambian children. Trans $R$ Soc Trop Med Hyg 1990, 84: 800-802.

25. Taelman, H., Clerinx, J., Kagame, A., Batungwanayo, J., Nyirabareja, A. \& Bogaerts, J. Cryptococcosis, another growing burden for central Africa. Lancet 1991, 338: 761. 
26. Zinsser, H. Rats, Lice and History. The History of a Bacillus. Macmillan, London, 1985.

27. McNeill, W.H. Plagues and Peoples. Penguin Books, Harmonsworth, Middlesex, 1979.

28. Smallman-Raynor, M.R. \& Cliff, A.D. Civil War and the spread of AIDS in Central Africa. Epidemiol Infect 1991, 107: 69-80.

29. Yarchoan, R., Venzon, D.J. \& Pluda, J.M. CD4 count and the risk for death in patients infected with HIV receiving antiretroviral therapy. Ann Intern Med 1991, 115: 184-189.

30. Surbone, A., Yarchoan, R., McAtee, N. et al. Treatment of the acquired immunodeficiency syndrome (AIDS) and AIDS-related complex with a regimen of $3^{\prime}$-Azido-2',3'dideoxythymidine (azidothymidine or zidovudine) and acyclovir. Ann Intern Med 1988, 108: 534-540.

31. National Eye Institute Press Release. US Department of Health and Human Services 1991, October.

32. Nordic Medical Research Council's HIV Therapy Group. Double blind dose-response study of zidovudine in AIDS and advanced HIV infection. Br Med J 1991, 304: 13-17.

33. Willocks, L., Cowan, F., Brettle, R.P., Emmanuel, F.X.S Flegg, P.J. \& Burns, S. The spectrum of chest infections in HIV positive patients in Edinburgh. J Infection 1992, 24: 37-42.

34. Farrer, G.H., Roff, M.A., Amin, T. et al. Characterization of a series of human immunodeficiency virus isolates derived sequentially from a single patient. J Med Virology 1991, 34: 104-113.

\section{Chickenpox}

35. Dunkle, L.M., Arvin, A.M., Whitley, R.J. et al. A controlled trial of acyclovir for chickenpox in normal children. $N$ Engl $J$ Med 1991, 325: 1539-1544.

36. Hardy, I., Gershorn, A.A., Steinberg, S.P., LaRussa, P. \& the Varicella Vaccine Collaborative Study Group. The incidence of zoster after immunisation with live attenuated varicella vaccine. $N$ Engl $J$ Med 1991, 325: 1545-1550.

\section{Childhood leukaemia}

37. Kinlen, L.J., Clarke, K. \& Hudson, C. Evidence from population mixing in British new towns 1946-85 of an infective basis for childhood leukaemia. Lancet 1990, 336: $577-582$.

38. Kinlen, L.J. \& Hudson, C. Childhood leukaemia and poliomyelitis in relation to military encampments in England and Wales in the period of national military service, 1950-63. Br Med J 1991, 303: 1357-1362.

\section{Chlamydia pneumoniae strain TWAR}

39. Grayston, J.T., Wang, S.P., Kuo, C.C. \& Campbell, L.A. Current knowledge on Chlamydia pneumoniae, strain TWAR, an important cause of pneumonia and other acute respiratory diseases. Eur J Clin Microbiol Infect Dis 1989, 8: 191-202.

\section{Chronic fatigue syndrome}

40. Lloyd, A.R., Wakefield, D., Broughton, R. \& Dwyer, J.M. Immunological abnormalities in the chronic fatigue syndrome. Med J Aust 1989, 151: 122-124.

41. Landay, A.L., Jessop, C., Lennette, E.T. \& Levy, J.A. Chronic fatigue syndrome: clinical condition associated with immune activation. Lancet 1991, 338: 707-712.

42. Lloyd, A., Hickie, I., Wakefield, D., Boughton, C. \& Dwyer, J. A double-blind, placebo-controlled trial of intravenous immunoglobulin therapy in patients with chronic fatigue syndrome. Am J Med 1990, 89: 561-568.

43. Peterson, P.K., Shepard, J., Macres, M. et al. A controlled trial of intravenous immunoglobulin $\mathrm{G}$ in chronic fatigue syndrome. Am J Med 1990, 89: 554-560.

44. Straus, S.E. Intravenous immunoglobulin treatment for the chronic fatigue syndrome. Am J Med 1990, 89: 551-552.
45. Dismukes, W.E., Wade, J.S., Lee, J.Y., Dockery, B.K. \& Hain, J.D. A randomised, double-blind trial of nystatin therapy for the candidiasis hypersensitivity syndrome. $N$ Engl J Med 1990, 323: 1717-1723.

46. Miller, N.A., Carmichael, H.A., Clader, B.D. et al. Antibody to coxsackie B virus in diagnosing postviral fatigue syndrome. $\mathrm{Br} \mathrm{Med} J$ 1991, 302: 140-143.

47. Gow, J.W., Behan, W.M.H., Clements, G.B., Woodall, C., Riding, M. \& Behan, P.O. Enteroviral RNA sequences detected by polymerase chain reaction in muscle of patients with postviral fatigue syndrome. $\mathrm{Br}$ Med $J$ 1991, 302: 692-696.

48. Josephs, S.F., Henry, B. \& Balachandrian, N. HHV-6 reactivation in chronic fatigue syndrome. Lancet 1991, 337: $1346-1347$.

\section{Cryptosporidiosis}

49. Joseph, C., Hamilton, G., O’Connor, M. et al. Cryptosporidiosis in the Isle of Thanet; an outbreak associated with local drinking water. Epidemiol Infect 1991, 107: 509-519.

50. Richardson, A.J., Frankenberg, R.A., Buck, A.C. et al. An outbreak of waterborne cryptosporidiosis in Swindon and Oxfordshire. Epidemiol Infect 1991, 107: 485-495.

51. Joce, R.E., Bruce, J., Kiely, D. et al. An outbreak of cryptosporidiosis associated with a swimming pool. Epidemiol Infect 1991, 107: 497-508.

\section{Enterohaemorrhagic Escherichia coli infections}

52. Riley, L.W., Remis, R.S., Helgerson, S.D. et al. Haemorrhagic colitis associated with a rare Escherichia coli serotype. N Engl J Med 1983, 303: 681-685.

53. Cryan, B. Enterohaemorrhagic Escherichia coli. Scand J Infect Dis 1990, 22: 1-4.

54. Martin, D.L., MacDonald, K.L., White, K.E., Soler, J.T. \& Osterholm, M.T. The epidemiology and clinical aspects of the haemolytic uremic syndrome in Minnesota. $N$ Engl $J$ Med 1990, 323: 1161-1167.

55. Carter, A.O., Borczyk, A.A., Carlson, J.A.K. et al. A severe outbreak of Escherichia coli 0157:H7 associated colitis in a nursing home. $N$ Engl J Med 1987, 317: 1496-1501.

\section{Gastroenteritis}

56. Harries, A.D., Beeching, N.J., Rogerson, S.J. \& Nye, F.J. The platelet count as a simple measure to distinguish inflammatory bowel disease from infective diarrhoea. $J$ Infection 1991, 22: 247-270.

57. Reilly, W.J., Oboegbulem, S.I., Munro, D.S. \& Forbes, G.I. The epidemiological relationship between salmonella isolated from poultry meat and sewage effluents at a long-stay hospital. Epidemiol Infect 1991, 106: 1-10.

58. Costello, A. M.de.L\& Bhutta, T.I. Antidiarrhoeal drugs for acute diarrhoea in children. $\mathrm{Br}$ Med J 1992, 304: 1-2.

59. Molla, A.M., Molla, A., Nath, S.K. \& Khatun, M. Foodbased oral rehydration salt solution for acute childhood diarrhoea. Lancet 1989, ii: 429.

Global warming: some consequences

60. Aitken, I.D. Global warming: some possible disease risks for the UK. Proc R Coll Physicians Edin 1991, 21: 393-396.

\section{Haemophilus influenzae type b infections: prevention}

61. Tudor-Williams, G., Frankland, J., Isaacs, D. et al. Haemophilus influenzae type b disease in the Oxford region. Arch Dis Child 1989, 64: 517-519.

62. Nazareth, B., Slack, M.P.E., Howard, A.J., Waight, P.A. \& Begg, N.T. Communicable disease report 1992, 2 (Rev 2): R13-16.

63. Howard, A.J., Dunkin, K.T., Musser, J.M. \& Palmer, S.R. Epidemiology of Haemophilus influenzae type $\mathrm{b}$ invasive disease in Wales. Br Med J 1991, 303: 441-445. 
64. Peltola, H., Kayhty, H., Sivonen, A. \& Makela, P.H Haemophilus influenzae type $\mathrm{b}$ capsular polysaccharide vaccine in children: a double-blind field study of 100,000 vaccinnees 3 months to 5 years of age in Finland. Pediatrics 1977, 60: 730-737.

65. Tudor-Williams, G., Frankland, J., Isaacs, D. et al. Haemophilus influenzae type b congugate vaccine trial in Oxford: implications for the United Kingdom. Arch Dis Child 1989, 64: 520-524.

66. Clements, D.A. \& Gilbert, G.L. Immunisation for the prevention of Haemophilus influenzae type b infections: $a$ review. Aust NZ J Med 1990, 20: 828-834.

67. Cartwright, K.A.V., Begg, N.T. \& Hull, D. Chemophrophylaxis for secondary Haemophilus influenzae type b disease. Communicable Disease Rep 1991, 1: R2-6.

68. Gilbert, G.L., MacInnes, S.J. \& Guise, I.A. Rifampicin prophylaxis for throat carriage of Haemophilus influenzae type $b$ in patients with invasive disease and their contacts. $\mathrm{Br}$ Med J 1991, 302: 1432-1435.

\section{Handwashing: will doctors ever learn?}

69. Conly, J.M., Hill, S., Ross, J., Lertzman, J. \& Louie, T.J. Handwashing practices in the intensive care unit: the effects of an educational program and its relationship to infection rates. Am J Infect Control 1989, 17: 330-339.

\section{Helicobacter pylori infection}

70. Sullivan, P.B. \& Thomas, J.E. Helicobacter pylori in children. Postgrad Med J 1991, 67: 330-333.

71. Nomura, A., Stemmermann, G.N., Chyou, P., Kato, I., Perex-Perez, G.I. \& Blaser, M.J. Helicobacter pylori infection and gastric carcinoma among Japanese Americans in Hawaii. N Engl J Med 1991, 325: 1132-1136.

\section{Hepatitis}

72. Phillips, M.J., Blendis, L.M., Poucell, et al. Syncytial giant-cell hepatitis: sporadic hepatitis with distinctive pathological features, a severe clinical course, and paramyxoviral features. $N$ Engl J Med 1991, 234: 455-460.

73. Anonymous editorial. Hepatitis G. Lancet 1991, 337: 1070.

74. Tozun, N., Forbes, A., Anderson, M.G. \& Murray-Lyon, I.M. Safety of alcohol after viral hepatitis. Lancet 1991, 337: 1079-1080.

\section{Hepatitis B}

75. Omata, M., Ehata, T., Yokosuka, O. \& Ohto, M. Mutations in the precore region of hepatitis B virus DNA in patients with fulminant and severe hepatitis. $N$ Engl J Med 1991, 324: 1699-1704.

76. Liang, T.J., Hasegawa, K., Rimon, N., Wands, J.R. \& Ben-Porath, E. A hepatitis B virus mutant associated with an epidemic of fulminant hepatitis. $N$ Engl J Med 1991, 324: 1705-1709.

77. Shafritz, D.A. Variants of hepatitis B virus associated with fulminant liver disease. N Engl J Med 1991, 324: 1737-1738.

78. Heptonstall, J. Outbreaks of hepatitis B virus infection associated with infected surgical staff. Communicable Diseases Rep 1991, R8: 81-85.

79. Liang, T.J., Baruch, Y., Ben-Porath et al. Hepatitis B virus infection in patients with idiopathic liver disease. Hepatology 1991, 13: 1044-1051.

Hepatitis C

80. Tedder, R.S., Gilson, R.J.C., Briggs, M. et al. Hepatitis C virus: evidence for sexual transmission. Br Med J 1991, 302: 1299-1302.

81. Tajima, K., Shimotohno, K. \& Oki, S. Natural horizontal transmission of HVC in microepidemic towns in Japan. Lancet 1991, 337: 1410 .

82. Wright, T.L., Hsu, H., Donegan, E. et al. Hepatitis C virus not found in fulminant non-A, non-B hepatitis. Ann Int Med 1991, 115: $111-112$.

83. Yanagi, M., Kaneko, S., Unoura, M. et al. Hepatitis C virus in fulminant hepatic failure. $N$ Engl J Med 1991, 324: 1985.
HTLV-I infection

84. Gessain, A., Barin, F., Vernant, J. et al. Antibodies to HTLV-I in patients with tropical spastic paraparesis. Lancet 1985, ii: 1247.

85. Murphy, E.L., Hanchard, B., Figeueroa, J.P. et al. Modelling the risk of ATLL in persons infected with HTLV-I. Int J Cancer 1989, 43: 250-253.

86. Kim, J.H. \& Durak, D.T. Manifestations of human Tlymphotropic virus type I infection. Am J Med 1988, 84: 919-928.

87. Williams, A.E., Fang, C.T., Slamon, D. et al. Seroprevalence and epidemiologic correlates of HTLV-I infection in US blood donors. Science 1988, 240: 6433-6436.

88. Hinoma, Y. Seroepidemiology of adult origin of virus carriers in Japan. AIDS Res 1986, 2: 517-522.

\section{Legionnaires' disease}

89. Bhopal, R.S., Falon, R.J., Buist, E.C., Black, R.J. \& Urquhart, J.D. Proximity of the home to a cooling tower and risk of non-outbreak Legionnaire's disease. $\mathrm{Br} \mathrm{Med} J$ 1991, 302: 387-383.

\section{Lyme disease}

90. Malane, M.S., Grant-Kels, J.M., Feder, H.M. \& Luger, S.W. Diagnosis of Lyme disease based on dermatologic manifestations. Ann Intern Med 1991, 114: 490-498.

91. Rahn, D.W. \& Malawista, S.E. Lyme disease: recommendations for diagnosis and treatment. Ann Intern Med 1991, 114: $472-481$.

92. Szer, I.S., Taylor, E. \& Steere, A.C. The long-term course of Lyme arthritis in children. $N$ Engl J Med 1991, 325: 159-163.

\section{Malaria}

93. Phillips-Howard, P.A., Radalowicz, J.M., Mitchel, J. \& Bradley, D.J. Risk of malaria in British residents returning from malarious areas. Br Med J 1990, 300: 499-503.

94. Bjorkman, A. \& Phillips-Howard, P.A. Drug-resistant malaria: mechanisms of development and inferences for malaria control. Trans $R$ Soc Trop Med Hyg 1990, 84: 323-324.

95. Muller, O. \& Moser, R. The clinical and parasitological presentation of Plasmodium falciparum malaria in Uganda is unaffected by HIV-1 infection. Trans $R$ Soc Trop Med Hyg 1990, 84: 336-338.

96. Warrell, D.A., Molyneux, M.E., Beales, P.F (eds). WHO Division of Control of Tropical Diseases. Severe and complicated malaria. Trans $R$ Soc Trop Med Hyg 1990, 84 (Suppl 2): 1-65.

\section{Monoclonal antibodies}

97. Glauser, M.P., Zanetti, G., Baumgartner, J.-D. \& Cohen, J. Septic shock: pathogenesis. Lancet 1991, 338: 732-739.

98. Ziegler, E.J., Fisher, C.J., Sprung, C.L. et al. Treatment of Gram-negative bacteraemia and septic shock with HA-1A human monoclonal antibody against antitoxin. $N$ Engl $J$ Med 1991, 324: 429-436.

\section{Plagues}

99. Mims, C.A. The origin of major human infections and the crucial role of person-to-person spread. Epidemiol Infect 1991, 106: 423-433.

\section{Pneumococcal vaccine}

100. Shapiro, E.D., Berg, A.T., Austrian, R. et al. The protective efficacy of polyvalent pneumococcal polysaccharide vaccine. $N$ Engl J Med 1991, 325: 1453-1460.

\section{Rabies}

101. Smith, J.S., Fishbein, D.B., Rupprecht, C.E. \& Clark, K. Unexplained rabies in three immigrants in the United States. N Engl J Med 1991, 324: 205-211. 


\section{Retroviruses}

102. Garry, R.F., Fermin, C.D., Hart, D.J., Alexander, S.S. Donehower, L.A. \& Luo-Zhang, H. Detection of a human intracisternal A-type retroviral particle antigenically related to HIV. Science 1990, 250: 1127-1129.

103. Anonymous. Editorial. What causes motorneurone disease? Lancet 1990, ii: $1033-1035$.

104. Hawkes, C.H. \& Graham, A.J. What causes motorneurone disease? Lancet 1991, 337: 180.

\section{Schizophrenia}

105. O'Callaghan, ?., Sham, P., Takei, N., Glover, G. \& Murray, R.M. Schizophrenia after prenatal exposure to 1957 A2 influenza epidemic. Lancet 1991, 337: 1248-1250.

\section{Gender and infections}

106. Pison, G., Aaby, P. \& Knudsen, K. Increased risk of death from measles in children with a sibling of opposite sex in Senegal. Br Med J 1992, 304: 284-287.

\section{Smoking versus bacteria}

107. Ertel, A., Eng, R. \& Smith, S.M. The differential effect of cigarette smoke on the growth of bacteria found in humans. Chest 1991, 100: 628-630.

\section{Travel}

108. Behrens, R.H. Protecting the health of the international traveller. Trans $R$ Soc Med Hyg 1990, 84: 611-612.

\section{Tuberculosis}

109. Rodrigues, L.C. \& Smith, P.G. Tuberculosis in developing countries and methods for its control. Trans $R$ Soc Trop Med Hyg 1990, 84: 739-744.

110. Stanford, J.L., Grange, J.M. \& Pozniak, A. Is Africa Lost? Lancet 1991, 338: 557-558.

\section{Yersinea enterocolitica infections}

111. Saebo, A. \& Lassen, J. A survey of acute and chronic disease associated with Yersinea enterocolitica infection. Scand $J$ Infect Dis 1991, 23: 517-527. 